\title{
Evaluating the South Memphis Farmers Market as a strategy to improve access to healthy foods: Lessons from 2011
}

\author{
Kathryn Hicks ${ }^{a *}$ and Katherine Lambert-Pennington ${ }^{a}$
}

University of Memphis

Submitted June 13, 2013 / Revised November 27, 2013, and January 18, 2014 / Accepted January 19, 2014 /

Published online March 19, 2014

Citation: Hicks, K., \& Lambert-Pennington, K. (2014). Evaluating the South Memphis Farmers Market as

a strategy to improve access to healthy foods: Lessons from 2011. Journal of Agriculture, Food Systems, and

Community Development, 4(2), 45-59. http://dx.doi.org/10.5304/jafscd.2014.042.014

Copyright (C) 2014 by New Leaf Associates, Inc.

\begin{abstract}
Limited access to fruits and vegetables is an issue for many low-income and minority neighborhoods and likely plays an important role in the development of health disparities. Local farmers' markets are a growing response to low-quality food environments, but can improve food security only if they are sustainable over the long term and broadly accessible to residents. The South Memphis Farmers Market emerged as one of the first actions from a participatory neighborhood planning and revitalization effort involving local nonprofits, neighborhood residents, and faculty and students from the University of Memphis in 2010, and maintains a local advisory committee to help tailor operational decisions to the neighborhood context. This paper is based on 2011 data from an ongoing mixed-methods evaluation of the market, designed
\end{abstract}

a Department of Anthropology, University of Memphis, Memphis, Tennessee.

* Corresponding author: Department of Anthropology, University of Memphis; 316 Manning Hall; Memphis, Tennessee 38152 USA; +1-901-678-2080;

kahicks2@memphis.edu to assess whether it is meeting the goals outlined in the neighborhood plan in terms of serving as an accessible source of fresh fruits and vegetables, and whether any changes to market policies are necessary to ensure its sustainability. This paper examines ethnographic data collected during participant observation in advisory committee meetings and during market hours, and quantitative data from an end-of-season survey of market shoppers. The analysis suggests that the market is expanding neighborhood access to produce, and that the guidance provided by the advisory committee has been essential to this success. It also highlights possible barriers to access and potential policy interventions to address them.

\section{Keywords}

evaluation, farmers' markets, federal nutrition benefits, healthy foods, low income, mixed methods, SNAP

\section{Introduction}

Residential areas offering limited access to fresh, healthy foods have emerged as a critical public health issue in recent years (Dinour, Bergen, \& 
Yeh, 2007; Eisenhauer, 2001; Lee, Gundersen, Cook, Laraia, \& Johnson, 2012; Walker, Keane, \& Burke, 2010). Food access is a multidimensional phenomenon, reflecting a mix of geographic, economic, social, and cultural factors. In a metaanalysis of published studies, Beaulac, Kristjansson, and Cummins (2009) found an interaction between neighborhood access to fresh food like fruits and vegetables and low socioeconomic status (SES) of households. They argue that "structural inequalities in the food retail environment" in low-income, minority neighborhoods amplify socio-economic barriers to accessing affordable, healthy food and "may contribute to inequalities in diet and dietrelated outcomes" (Beaulac et al., 2009, pp. 4-5). Recent research has shown that food in some urban neighborhoods is more costly and limited in quality and type (Hendrickson, Smith, \& Eikenberry, 2006). Additional explanations for this relationship between economic circumstances, socioeconomic status, and health include an inverse association between the energy density of available foods and their costs, and constraints on access to transportation (Dinour et al., 2007; Drewnowski \& Darmon, 2005; Larsen \& Gilliland, 2008; Schroder, Marrugat, \& Covas, 2006).

Recent reviews provide evidence for a link between food environment and health (Larson, Story, \& Nelson, 2009; Michimi \& Wimberly, 2010; Walker et al., 2010). In general, diets high in fresh fruits and vegetables are associated with lower rates of obesity and central adiposity, as well as related conditions such as diabetes (Baxter, Coyne, \& McClintock, 2006; Hu, 2003; Roblin, 2007). A number of studies have found that neighborhood access to supermarkets and full-service restaurants predicts fruit and vegetable consumption, controlling for income (Izumi, Zenk, Schulz, Mentz, \& Wilson, 2011; Kamphuis, Giskes, de Bruijn, Wendel-Vos, Brug, \& van Lenthe, 2006). Similarly, neighborhood food access is related to the risk of obesity (Gibson, 2011; Rundle et al., 2009; Zick, Smith, Fan, Brown, Yamada, \& Kowaleski-Jones, 2009). Crucially, persistent residential segregation and uneven economic development in neighborhoods occupied primarily by people of color contributes to systematic inequalities in healthy food access and to the development of health disparities (Drewnowski \& Darmon, 2005; Larson et al., 2009; Walker et al., 2010).

In response to the ongoing difficulty associated with attracting large grocery stores and supermarkets to inner-city neighborhoods (Eisenhauer, 2001), a number of communities have instituted local farmers' markets to enhance seasonal access to affordable fresh fruits and vegetables (Boyle, Stone-Franciso, \& Samuels, 2006; George, Kraschnewski, \& Rovniak, 2011; Larsen \& Gilliland, 2009; Markowitz, 2010; Ruelas, Iverson, Kiekel, \& Peters, 2012; Young, Karpyn, Uy, Wich, \& Glyn, 2011). Not only are farmers' markets an urban food intervention, but they also play an important role in rebuilding local food systems (Gillespie, Hilchey, Hinrichs, \& Feenstra, 2007; Lyson, Gillespie Jr., \& Hilchey, 1995), urban revitalization (Bubinas, 2011; Faulk, 2006; Reardon, 1998), and community building (Payet, Gilles, \& Howat, 2005; Szmigin, Maddock, \& Carrigan, 2003). Despite the generally positive impact of farmers' markets, some research has shown that markets in low-income neighborhoods face economic challenges — including difficulty attracting shoppers and farmers - that constrain food access or food justice aims (Alkon, 2008; Guthman, Morris, \& Allen, 2006; Markowitz, 2010; Winne, 2008). A number of studies suggest that farmers' market coupon programs help attract shoppers and increase their consumption of fruits and vegetables during the summer months (Anliker, Winne, \& Drake, 1992; Balsam, Webber, \& Oehlke, 1994; Herman, Harrison, Afifi, \& Jenks, 2008; Johnson, Beaudoin, Smith, Beresford, \& LoGerfo, 2004; Racine, Smith Vaughn, \& Laditka, 2010), and that markets may exert downward pressure on neighborhood food prices by increasing competition (Larsen \& Gilliland, 2009). Both farmers and customers benefit from direct sales and federal subsidies: for example, the Special Supplemental Nutrition Program for Women, Infants, and Children (WIC) and Senior Farmers' Market Nutrition Programs (SFMNP), the Supplemental Nutrition Assistance Program (SNAP), and a number of competitive USDA grants for market development (Becker, 2006). Additionally, Markowitz (2010) suggests that the success of markets in low-income neighborhoods depends heavily on community engagement and collabora- 
tion with local institutions.

Growing scholarly focus on farmers' markets reflects their increasing frequency in the US since the 1970s (Brown, 2001), but evidence of their effectiveness as an intervention to address neighborhood food environments and quality of life is limited (McCormack, Laska, Larson, \& Story, 2010). In addition to longitudinal studies assessing the relationship between access to farmers' markets and health outcomes such as body composition (e.g., obesity risk), scholars have argued for the need to explore the social benefits of markets (Andreatta \& Wickliffe, 2002; McCormack et al., 2010). Important for understanding the health impact of local markets is assessing whether they are accessible and attractive to a broad range of residents, and whether their practices are sustainable over the long term. Opening a market may not be sufficient to increase neighborhood access to healthy foods if the same influences that constrain food purchasing choices prevent individuals from attending, and if the market cannot meet operational demands.

Aware of the relationship between accessing quality, affordable food, revitalizing the neighborhood, and alleviating health disparities, The Works, Inc., a community development corporation, in conjunction with a resident advisory committee, established the South Memphis Farmers Market (SMFM) in mid-summer 2010. Starting in 2011, faculty and students from the University of Memphis worked with the advisory committee, which is made up of two to five resident-volunteers, representatives from two nonprofits that support the market, and staff from The Works, Inc., to conduct a systematic evaluation of the SMFM to assess the nutritional, economic, and social impacts of the market, and to identify specific strategies for enhancing its effectiveness as an intervention to improve access to healthy foods. This paper, based on analysis of ethnographic and survey data, explores customer characteristics and perceptions of the market, with an emphasis on determining whether the market is meeting the healthy food access goals outlined by residents in the SoMe Revitalization Action Plan (SoMeRAP), a participatory neighborhood planning initiative. We use multiple logistic regression analysis to examine what characteristics are significant predictors of shopping frequency and spending at the market, and to determine whether there is any evidence of systemic barriers to access which might be addressed. We complete this exploratory analysis with a discussion of changes or improvements that might be necessary to ensure the market's sustainability, and lessons learned from the evaluation.

\section{Program Description}

South Memphis is a predominately African-

American residential neighborhood in the urban core of Memphis. According to the 2010 Census, 29.8 percent of South Memphis adults over the age of 25 years did not graduate from high school, 28.4 percent of eligible workers were unemployed, and median household incomes trailed both those of the state by over 49 percent and the nation by 41 percent. In addition, nearly 37 percent of families lived in poverty and approximately 51 percent of these households had children under the age of 18 . At the same time, a stable base of long-time homeowners and well-respected civic, social, and faithbased institutions are among the area's most important assets and change agents (LambertPennington \& Reardon, 2009).

The Works, Inc., was established in 1998 by the local St. Andrew African Methodist Episcopal (AME) Church to address housing and social development needs within the community. These organizations approached faculty at the University of Memphis in 2008 to help facilitate these goals through a neighborhood planning process, leading to the SoMeRAP partnership. The focus of SoMeRAP is an area consisting of 140 blocks within the greater South Memphis community which makes up The Works, Inc., service area. Participatory planning, also known as an empowerment (Reardon, 2005) or equity model of planning (Reardon, Ionescu-Heroiu, \& Rumbach, 2008), is a community-based strategy taking its cues from participatory action research (PAR), Saul Alinskystyle direct-action organizing, and Freire-inspired popular education (Freire, 2000). In contrast to a professional and expert-driven model of neighborhood planning, participatory planning prioritizes the expertise, insights, and priorities of local residents and stakeholders in the research, analysis, 
planning, and action phases of the process. Residents of the neighborhood and faculty and students from the University of Memphis worked together to collect and analyze data about the neighborhood, including land use and building condition surveys; interviews with more than 50 residents, organizational leaders, and other stakeholders; 174 door-to-door surveys; and facilitation of four community forums (Lambert-Pennington, Reardon, \& Robinson, 2011). Through this process, residents identified nine overall development objectives and over 40 specific projects, and committed to working together on their top priorities, one of which was improving the neighborhood food environment. SMFM is one of the first projects resulting from SoMeRAP.

Over 6800 people live within The Works, Inc.'s service area, which has been identified as a food desert due to the absence of a full-service grocery store within one mile $(1.6 \mathrm{~km})$ and low median income of local households (U.S. Department of Agriculture, 2013). Research conducted for the SoMeRAP suggests that food-related retail operations in or near the neighborhood are largely limited to convenience and corner stores, small grocery stores, and some fast-food restaurants (Lambert-Pennington \& Reardon, 2009). In the door-to-door survey, residents reported travelling two to five miles (3.2 to $8.0 \mathrm{~km}$ ), often by bus or car, to purchase their weekly groceries. During the SoMeRAP action group discussions, women with children often discussed their difficulties with taking the bus, especially transporting their food home from the store. The closest store is 1.5-2.5 miles $(2.4-4.0 \mathrm{~km})$ from the neighborhood (depending on what area of the neighborhood a resident lives in). Residents cited this outlet as a store of last resort, reporting poor quality and selection, as well as lack of cleanliness. The two grocery stores most often frequented by residents are three miles $(4.8 \mathrm{~km})$ away from the neighborhood; travel on public transit requires changing buses en route and takes about 45 minutes each way. Thus, some residents opted to hire a taxi for the return trip, which reduced the funds available to spend on food.

Residents pushed to make a farmers' market a top neighborhood redevelopment priority to begin to address this deficit and its negative health impacts. St. Andrew AME quickly responded to the residents' call by donating an unused commercial space to The Works, Inc., for the market. A group of SoMeRAP participants volunteered to serve as the advisory committee. Within two months, the façade of "Old Carter's Fish Market," widely recognized as a former neighborhood institution, was colorfully transformed by a mural featuring fresh vegetables, painted by local youth in the lead-up to the market's opening in July 2010. The goals of the SMFM are to provide "access to healthy and affordable foods in the South Memphis community" and to "strive to create an atmosphere that contributes to the success of local growers and producers" (South Memphis Farmers Market, 2013). The Works, Inc., in association with the advisory committee, runs the SMFM. Staffed primarily by volunteers, the market is open on Thursdays from 12:00 PM to 6:00 PM between May and October. Extending the participatory practices and expectations of the SoMeRAP process, residents on the advisory committee played a key role in setting market rules and vendor guidelines. Drawing on their understandings of and experiences in the local food environment, they prioritized keeping the market small and accessible to local residents and maintaining a focus on fresh fruits and vegetables by (1) limiting the number of vendors to 10 overall and allowing no more than two non-food vendors; (2) keeping vendor fees low to encourage participation in the market; (3) allowing limited resale to increase produce variety;

(4) placing no restrictions on growing practices; (5) relying on volunteer labor; and (6) prioritizing SNAP and SFMNP voucher acceptance.

The SMFM began accepting SNAP Electronic Benefits Transfer (EBT) cards during the 2011 season. Although there are more markets that currently accept SNAP in Memphis, SMFM was one of only two in 2011. Additionally, the market began participating in the Wholesome Wave Foundation's Double Value Coupon Program, referred to by market staff as "Double Green\$," which matches up to US\$10 of SNAP purchases each week. The market also recruited several farmers approved by the Shelby County Health Department to redeem SFMNP vouchers. Seniors 
generally receive US $\$ 40$ in vouchers that they can spend only during the months of July and August. The SFMNP system had proved controversial in 2011, as seniors faced long waits in intense heat for the small number of approved vendors at the downtown Memphis Farmers Market (Alexander, 2011). Learning from the experience of this larger market, volunteers at the SMFM set up a seating area under the small permanent canopy, asked shoppers to sign in, and called them up in groups of 25 to shop. In the subsequent year, more farmers were approved to take the vouchers, and seniors had several additional markets they could choose to attend.

\section{Methods}

The SMFM research team consisted of two faculty members (the authors), three anthropology students (two graduate students and one undergraduate), and the market's advisory committee. In keeping with the participatory orientation of SoMeRAP, we worked with members of the advisory committee to design and test each component of our research strategy. Representatives from The Works, Inc., provided weekly shopper and vendor counts, and values of SNAP, Double Green\$, and debit and credit card transactions. The University of Memphis Institutional Review Board approved the study procedures.

\section{Participant Observation}

The research team conducted observations in the course of participating in the weekly advisory committee meetings and volunteering at the market. During the committee meetings we engaged in discussions of any issues that emerged in prior weeks of market planning, and sought interpretation of observations from residents. At each market we helped with setup and operation, engaged in informal conversations with farmers, shoppers, and volunteers about issues such as produce availability, preparation strategies, and the neighborhood food environment, and made descriptive observations. During most market days we also conducted structured data collection, which focused on identifying where shoppers lived and the variety and availability of produce. For example, we periodically set up a poster-sized map of the city and asked shoppers to place a stickerdot on their nearest cross-streets: we collected three maps throughout the course of the season. We also recorded the products available from each vendor, and interval inventories of purchases. We compiled electronic copies of field-notes and data records in a central database for later analysis.

\section{End-of-Season Surveys}

In the last two weeks of the market season, during October 2011, we conducted an anonymous survey of shoppers over the age of 18. Following the participatory nature of the project, the surveys were constructed in collaboration with staff from The Works, Inc. based on shared research objectives. We tested the survey with members of the advisory board, including several community residents, over two meetings. Members took the survey, suggested a number of changes in wording and other changes, and then reviewed these changes the following week. The goal was to collect 150 surveys over this two-week period. In order to determine the appropriate sample size, we based our power calculations on an estimate of the total number of shoppers over the season based on weekly shopper counts taken by members of The Works, Inc. The final survey included 39 questions and focused on the following dimensions:

- Shopping frequency

- Levels of satisfaction with various aspects of the market

- Shopping and eating behaviors

- Health concerns or conditions

- Suggestions for expanding items and programming at the market

Additionally, we collected demographic information such as age, gender, employment, and monthly income. We were most interested in the difference between shoppers in the lowest income category and everyone else. Aware of residents' comfort in reporting monthly rather than annual income, we converted the annual income categories standard in the U.S. Census and used in SoMeRAP to monthly categories.

With the help of vendors, staff, and advisory board members, over the full course of each of the 
two market days we solicited anonymous surveys from each shopper. This sampling strategy is similar to that used in other studies of farmers' markets (Ruelas et al., 2012). We offered assistance in filling out the survey where necessary. Participants received an incentive of a US $\$ 10$ grocery card or the equivalent in market tokens. A graduate research assistant entered responses into Qualtrics 2012 software (Qualtrics Labs, Inc., Provo, Utah).

\section{Data Analysis}

We carried out qualitative analysis of ethnographic field notes, coding for both pre-determined and emergent themes. Some of the domains we explored were perceptions of the market, social interactions, and discussions of produce and preparation techniques.

We carried out statistical analyses of the survey data using Stata 10.0 (Statacorp, College Station, Texas). In addition to compiling descriptive statistics, we used multiple logistic regression analysis to explore which characteristics predict 1) being a frequent market attendee (average attendance $\geq$ twice a month) relative to being a first-time or infrequent shopper, and 2) spending, on average, more than US $\$ 15$ at the market per visit, excluding first-time shoppers. To check the validity of including first-time shoppers in the first model, the same analysis was run without this group to determine whether the results were substantially different (they were not). In the first stage of analysis, age in years, monthly take-home income (modeled as a dummy variable for income $>$ US \$800), the number of household members, and gender were entered as potential confounders. To preserve degrees of freedom, variables that were not significantly related to the outcome were excluded. In the second stage, potential predictors were added as a group and $p$ levels and goodness of fit tests were used to determine which predictors to exclude from the final models. In both models, these included being a neighborhood resident, driving to the market, eating frequently at restaurants, having a household member with a chronic disease, employment status, and using EBT or SFMNP vouchers to purchase produce. Finally, we ran a series of diagnostic procedures to assess the validity of each final model including tests for multicollinearity, or strong relationships between predictor variables, and for undue influence by outlying observations (there was no evidence of these issues in the models below). We used a significance level of 0.05 .

\section{Results}

Weekly shopper counts indicate that approximately 3, 226 people came to the market from the last week of June through the end of the market in 2011, and the number of shoppers per week ranged from 90 to 378 with a mean number of 215 (see figure 1). Observations indicated that attendance peaked during the months of July and August when seniors were able to cash their SFMNP vouchers. In fact, operators and farmers agreed to start two or three hours earlier during those months to handle the increased volume of traffic. Seventy-one percent of survey respondents were residents of one of the surrounding neighborhoods. This finding is consistent with the interactive mapping exercise, which showed that the bulk of shoppers lived within a one-mile $(1.6 \mathrm{~km})$ radius of the market. Informal discussions with shoppers indicated that many of those from outside the neighborhood worked in the area and had discovered the market while passing by. SMFM sits on an alternate trucking route just off an interstate highway, so there is a relatively high flow of vehicle traffic during business hours. Most respondents said that they attended either every week (39 percent) or every other week ( 25 percent), but 23 percent $(n=26)$ were coming to the market for the first time the day of the survey.

Thirty-one percent of survey participants were employed for wages, 26 percent were retired, and 31 percent were unable to work or currently unemployed. Thirty-eight percent reported a monthly household take-home income of US $\$ 800$ or less, which is below the 2011 poverty threshold of roughly US $\$ 1,221$ a month for a two-person household (US Census Bureau). The average household size among survey respondents was 3.2 persons. Sixty percent reported spending between US $\$ 100$ and US $\$ 300$ each month on groceries for their household, including SNAP benefits. The largest proportion of people got to the market by driving but many walked (27 percent) or caught a 
ride with a family member, neighbor or friend (24 percent). Finally, 37 percent of the individuals in the sample reported having made changes to their diet to deal with a health condition, which ranged from eating less salt and fried foods to eating more fruits and vegetables and changing portion sizes.

Of the individuals who had attended the market previously, the vast majority reported high levels of satisfaction with its operation. Virtually all respondents said they were very satisfied or satisfied by the variety, quality, affordability, location, parking opportunity and days of operation of the market, although in written responses a small number of people did suggest opening the market more than one day a week, improving spatial organization, and offering a greater variety of produce. Ninety-three percent of all shoppers thought that they saved money by shopping at this market, because they did not have to travel a long distance outside the neighborhood, because of the freshness of the produce (lasted longer/threw less away), or because they perceived the prices to be competitive with local supermarket chains. The similarity in responses across attendance categories supports the conclusion that, at least among this particular sample, lower attendance frequency is not a result of dissatisfaction with the market, and that produce is relatively affordable.

A common perception expressed by both

\section{Figure 1. Monthly Attendance, Credit Card and Debit (US\$), and SNAP and Double Greens Sales (US\$) for the 2011 Season}

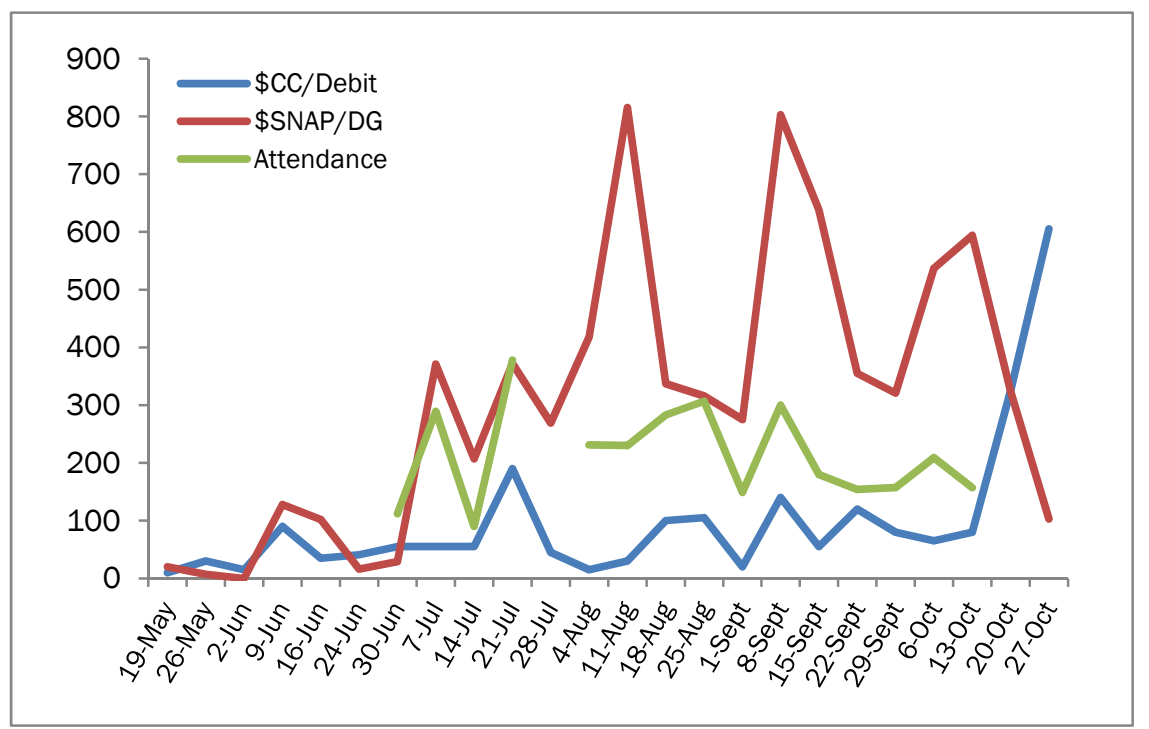

customers and farmers is that SMFM is among the most friendly and informal of all the markets in the city. Farmers noted that they receive more volunteer assistance, and that customers are more likely at this market than others to return in subsequent weeks to express their appreciation after making a purchase. A local bus driver's reaction to the market illustrates this sense of community: Driving the route with a stop right in front of the vendors, this woman would often open the door to socialize and ask farmers what they were selling. She was a strong advocate of the market, and on several occasions she stopped to allow passengers time to shop. The downside of the informality of the market is illustrated by several comments from shoppers and passersby that the market did not look "serious," and the distress expressed by volunteers and vendors when food wrappers and other trash would start to pile up on the site.

When asked in the survey to identify what forms of payment they use, most shoppers reported relying on cash (86 percent), while up to 32 percent used SNAP and a much smaller number used SFMNP vouchers (6 percent) and credit or debit cards ( 9 percent). Around 60 percent of those who used SNAP and SFMNP added to their purchases with other forms of payment. On average, SNAP purchases were just over US $\$ 10$, which suggests that many shoppers were spending just enough to maximize their Double-

Green\$ tokens. Informal conversations with customers suggest that SNAP shoppers may shop at the market every week, and reserve some of their tokens for the end of the month when they have run out of EBT and cash. The majority of shoppers (74 percent) spent between US\$6 and US\$20 each visit. Figure 1 illustrates the weekly values of SNAP/

Double Greens and credit/debit card purchases, and shopper counts when available, from each week of operation. Sales from these sources throughout the season 
were US\$9,718. Given the high reported use of cash and the increased volume of shoppers during the SMFMP, total market sales were likely much higher. SNAP purchases (and, likely, other forms as well) started the season relatively slow, but rose in July, and peaked in August and September, possibly associated with the adoption of the Double Green \$ matching program, the higher traffic volume related to SFMNP vouchers, and increased variety due to the peak season for harvesting.

We ran a number of bivariate tests of association to determine if there were significant differences between neighborhood residents and nonresidents who attend the market, to assess the possibility that non-resident shoppers have a higher SES than resident shoppers. In particular, we were interested in exploring the potential implications of attendance and payment type for the longterm sustainability of the market. This was based on qualitative evidence that individuals from outside the neighborhood were often passing by, possibly on their way to or from work, and on the work of other authors suggesting that attracting cash from outside the neighborhood might be an important component of long-term sustainability (George et al., 2011). There is no evidence that nonresidents were more likely to have higher income, or to be employed for wages; however, they were more likely to use cash or credit and debit cards exclusively for purchases $\left(X^{2}=5.60\right.$, $\mathrm{p}=0.02)$.

Vendor participation ranged from one during the slowest weeks to nine at the height of SFMNP voucher season in July. Two vendors who attended almost every week of the market were responsible for a majority of SNAP and debit and credit card purchases, and their sales were relatively consistent throughout the season. Four vendors were approved to take SFMNP vouchers and attended the market exclusively during the months of July and August. Conversations with participating vendors suggest that SMFM does a high volume of SFMNP sales relative to other Memphis area markets, and that this market makes a significant contribution to these farmers' total sales during this period.

Vendors also commented on the relatively high volume of SNAP sales at this market, and the peak of these sales during the first one to two weeks during each month, just after EBT cards have been reloaded. Thus, during the spring and fall months, when attendance is lower and quantity of produce is smaller, the market can support fewer vendors. Finally, farmers note that shoppers are most interested in buying tomatoes, green tomatoes, okra, greens, and fruit like peaches, plums, and melons, all of which are highly seasonal. Although greens are available early on and late in the season, conversations with customers and passersby indicate that the absence of fruit may be one reason for the relatively lower attendance in May and June.

Table 1 displays selected descriptive characteristics from the end-of-season survey for frequent and less-frequent market shoppers.

Table 1. Characteristics of Frequent ( $\geq 2 x$ visits per month) and Less Frequent Market Attendees

\begin{tabular}{lccc}
\hline Characteristic & $\begin{array}{c}\text { Infrequent }(\mathbf{N}=\mathbf{4 1}) \\
\%\end{array}$ & $\begin{array}{c}\text { Frequent }(\mathbf{N}=\mathbf{7 2}) \\
\%\end{array}$ & $\begin{array}{c}\text { Total (N=113) } \\
\%\end{array}$ \\
\hline Neighborhood resident & 66 & 76 & 72 \\
Uses EBT & 41 & 25 & 32 \\
Female & 58 & 67 & 64 \\
Monthly take-home pay $\leq$ US $\$ 800$ & 44 & 35 & 38 \\
Employed for wages & 30 & 32 & 31 \\
Retired & 5 & 38 & 26 \\
Eats out $\geq$ 3x per week & 42 & 20 & 29 \\
Household member is diabetic & 44 & 33 & 35 \\
Household member has high BP & 44 & 61 & 55 \\
No. of Household residents (mean, (S.D.)) & $3.8(2.0)$ & $2.8(1.7)$ & $3.2(2.1)$ \\
Age (mean, (S.D.)) & $43.1(13.4)$ & $56.9(14.6)$ & $51.9(14.8)$ \\
\hline
\end{tabular}


Table 2. Odds Ratios and $95 \%$ Confidence Intervals for Logistic Regression Model Predicting High Market Attendance Log likelihood $=-42.89 \mathrm{~N}=93$

\begin{tabular}{lcc}
\hline Characteristic & Odds Ratio $(95 \%$ CI) & P Value \\
\hline Age & $1.08(1.03-1.12)$ & 0.00 \\
Monthly take-home pay $\geq$ US\$800 & $0.52(0.15-1.79)$ & 0.30 \\
Neighborhood residence & $5.61(1.53-20.53)$ & 0.01 \\
Drives & $4.56(1.33-15.58)$ & 0.02 \\
Eats out $\geq 3$ times a week & $0.30(0.09-0.99)$ & 0.05 \\
Uses SNAP or SFMNP & $0.36(0.11-1.22)$ & 0.10 \\
\hline
\end{tabular}

Table 3. Odds Ratios for Logistic Regression Model Predicting Average Spending of $\geq$ US\$15

Log likelihood $=-34.35 \mathrm{~N}=72$

\begin{tabular}{lcc}
\hline Characteristic & Odd Ratio $(95 \%$ Cl) & P value \\
\hline Age & $1.03(1.00-1.08)$ & 0.85 \\
Monthly take-home pay $\geq$ US\$800 & $2.97(0.79-11.24)$ & 0.11 \\
Uses SNAP or SFMNP & $6.37(1.63-24.82)$ & 0.01 \\
Household member is diabetic & $4.10(1.25-13.47)$ & 0.02 \\
\hline
\end{tabular}

Multivariate Analysis

Table 2 displays the results of the logistic regression analysis predicting the likelihood of being a frequent market shopper. In the base model including age, gender, income, and household size, only age was significantly related to this outcome, but income was left in the model to control for socioeconomic status. Survey participants had significantly higher odds of shopping frequently at the market if they were a resident of the surrounding neighborhood, drove, or were older, and had significantly lower odds if they ate out frequently, controlling for monthly income. There is no evidence that having a chronic health condition or receiving federal nutrition benefits was related to the frequency of market attendance. The

Frequent market attendees were older and lived in smaller households, and a higher percentage of them were female, retired, neighborhood residents, and lived in a household with someone who has high blood pressure. In contrast, a higher percentage of infrequent shoppers used SNAP, had a monthly take-home income of US $\$ 800$ or less, ate out three or more times a week, and lived with someone who is diabetic. Bivariate tests of association indicate significant differences between frequent and infrequent shoppers only in the proportions of retired people $\left(\mathrm{X}^{2}=14.49, \mathrm{p}=0.00\right)$ and people who eat out frequently $\left(X^{2}=6.61\right.$, $\mathrm{p}=0.01)$, although there is a marginal association between shopping frequency and SNAP use $\left(\mathrm{X}^{2}=3.31, \mathrm{p}=0.07\right)$. A relatively large proportion of all survey participants lived in households with someone who has a chronic health issue, and several respondents reported more than one of these conditions. Having a household resident with high blood pressure, but not diabetes, was significantly related to age (Kruskal-Wallis Test, $\left.\mathrm{X}^{2}=5.50, \mathrm{p}=0.01\right)$. association between driving and market attendance may relate exclusively to ease of getting to the market, even within the neighborhood, but it may also be an indirect measure of SES and purchasing power. We further tested for an interaction between driving and residence, but this term was not a significant predictor of attendance. A chisquare test reveals that driving and take-home income are significantly and positively related to one another $\left(X^{2}=19.13, \mathrm{p}=0.00\right)$, supporting the second of these interpretations, although they are certainly not mutually exclusive. We also wondered whether frequency of outside eating might relate to take-home income, but found no association between these variables $\left(\mathrm{X}^{2}=0.42, \mathrm{p}=0.52\right)$.

Table 3 displays the results of the logistic regression analysis predicting the likelihood of spending, on average, US $\$ 15$ or more at the market. Controlling for age and income, shoppers had higher odds of spending $\geq$ US $\$ 15$ if they received government subsidies, such as SNAP or SFMNP vouchers, and if a member of their household was diabetic. Neither age nor income was a significant predictor of spending, although they were both positively associated with this outcome. A chi- 
square test indicates that the two outcome variables are also related to each other: people who attend the market more frequently are more likely to spend more than US $\$ 15\left(\mathrm{X}^{2}=7.13, \mathrm{p}=0.01\right)$.

\section{Discussion}

The quantitative analysis provides some important insights about who is more likely to shop at the market. The association between neighborhood residence and shopping frequency is consistent with the prediction of the research team and the objectives of SoMeRAP. Memphis now boasts at least 14 markets, and SMFM is among the smaller markets in the city, so it is unlikely to serve as a destination for nonresidents who are not already driving in its vicinity. There are, however, no other markets within one mile of this neighborhood. An ongoing question for the advisory committee and market operators is how widely to advertise the market beyond the immediate neighborhood. Increased attendance may contribute to the longterm sustainability of the market, but this must be balanced with the potential influence of increased traffic on prices, and the need to avoid direct competition with other markets and potential loss of business. The finding that nonresidents are more likely to pay for their purchases with cash or credit and debit cards suggests that working to attract shoppers en route past the market, perhaps through high-impact permanent signage, is an important strategy to enhance sustainability.

The association between attendance and age may mean that older residents place a higher value on fresh produce, but it also may relate to the timing of the market. Operating hours of 12:006:00 PM on a weekday may reduce the attendance of individuals in the labor force. These results may even underestimate the influence of age on attendance. The busiest time for the market is in the two-month period (July-August) during which SFMNP vouchers are redeemed. This is likely influenced partly by the small number of vendors throughout the city approved to take these vouchers. The fact that only seven of the survey participants were SFMNP users may suggest that some of these shoppers attend the market only during voucher season. These results point to a need to investigate further the influence of market hours on accessibility. This will include conducting separate surveys amongst SFMNP voucher shoppers to determine if and why they may be less likely to attend during non-voucher season.

Another need that has been identified is to prioritize outreach and education among younger residents. One way SMFM is beginning to address this is cooperation with a learning farm program. During the summer months, local youth help to grow organic produce within the neighborhood, and bring surplus produce to sell at the market. In addition, in 2012 the SMFM received a USDA Farmers Market Improvement Grant to renovate the former fish market to serve as a small grocery store and education kitchen. Eventually, they plan to offer fresh fruits and vegetables most days of the week throughout the year. The advisory board will consider additional strategies, including having a local school club volunteer during market hours.

The analysis of spending patterns also provides evidence about market accessibility and suggests avenues for further investigation. Both frequent and less-frequent shoppers perceive SMFM produce as affordable and of high quality relative to grocery stores. The efforts of the advisory committee and staff to minimize operational costs likely play an important role here. The lack of association between shopper spending and income and the positive association with benefits-use support the conclusion that nutritional subsidy programs increase residents' purchasing power. One important factor is likely the enrollment of the market in the "Double Green\$" program run by the Wholesome Wave Foundation, which provides up to US $\$ 10$ weekly in additional market tokens to SNAP users. The positive relationship between spending and diabetes may reflect higher overall food expenditures or differential expenditures by this population in order to manage their chronic health conditions. If the latter is true, diabetic residents may prioritize spending on produce as a result of targeted nutritional education. A potential avenue for expanding participation in the market may be active collaboration with these education programs. Alternatively, it is possible that individuals from non-diabetic households procure more produce from other food outlets, although it is unclear what factor(s) would motivate this 
differential spending. Additional research is needed to explore these findings.

These results also point to some potential ongoing barriers to participation in the market that staff and volunteers will need to address. Although income was not significantly related either to attendance or spending, a higher proportion of individuals attending for the first time the day of the end-of-season survey lived in low-income households. Ethnographic observations conducted by the research team support the conclusion that the US $\$ 10$ grocery incentive was a significant draw to people who may not have felt able to attend the market in the past, though we did not advertise either the survey or incentive in advance of data collection. Interestingly, the majority of survey participants chose tokens for the SMFM over a gift card for the local supermarket chain. The negative association between shopping frequency and frequency of eating at restaurants may provide insight into priorities in food purchasing decisions. One potential explanation for this pattern is that consuming restaurant food, particularly from fast food chains, may be an efficient way to maximize calories given a limited household food budget. This helps explain why the density of fast-food restaurants is negatively associated with fruit and vegetable consumption (Larson et al., 2009). Our analysis provides no evidence for a relationship between income and eating outside the household. Alternative explanations are that people who work are both more likely to eat at restaurants and to be away during market hours, or that there are systematic differences between these populations in terms of either food preference or time available for cooking at home. The higher frequency of attendance among residents who drive points to potential barriers in terms of household socioeconomic status and mobility. Over time, market staff will consider the possibility of following the example of other markets in offering transportation subsidies to local organizations to bring residents to the site (George et al., 2011).

These results broadly support the conclusion that local perceptions of the market are very positive. This market appears to fill a niche in the city's alternative and local food system, in terms of serving residents of South Memphis who may be less likely to attend larger area markets and providing economic benefit to local producers. We argue that the involvement of the advisory committee in decision making and operation is critical to this success. Their on-the-ground appreciation of the practices, desires, and limitations related to the local food environment are often the focus of weekly advisory committee meetings and the basis for changes in the operation of the market. Perhaps as important, members of the advisory committee from the local community share their enthusiasm for the market with members of their social circles. During market hours they greet and socialize with shoppers and discuss producepreparation techniques and recipes. They also assist farmers and shoppers; for example, carrying produce to cars and sometimes driving shoppers home with their goods. These activities make an invaluable contribution to the informal and friendly atmosphere of the market relative to other sites.

Our analysis also highlights the importance of continuing to work to keep prices relatively low and to attract SNAP and SFMNP shoppers. The market clearly had the largest economic impact for farmers in July and August, largely because of the high rate of SFMNP redemption. As the number of approved SFMNP vendors rises and shoppers are able to redeem their benefits at more city markets, SMFM may do a lower share of this business. One potential strategy might be to partner with local seniors' centers or residences to transport people to the market.

Patricia Allen (1999), in her exploration of both the potential benefits and limitations of community-based, entrepreneurial responses to food-system inequalities, concludes that food justice and prioritization of local food systems are not inherently compatible. Programs working to link local production and consumption with the needs of low-income communities are an important piece of the puzzle, but they are not, by their very nature, comprehensive, or free from market forces and fluctuations in grant funding (Allen, 1999). Federal social safety net programs remain essential for improving access to healthy foods among low-income communities. This conclusion is supported by our research on the SMFM.

Although cash and credit and debit card sales 
predominate, nutritional benefits programs clearly drive up levels of attendance and increase purchasing power. While the market might be able to succeed with fewer vendors should subsidy programs disappear, the potential nutritional and social impact of the market would be lessened, and economic stimulus to local producers would be reduced in their absence. An important potential avenue of collaboration for Shelby County Farmers Markets would be to develop a lobbying strategy to advocate for WIC FMNP participation, to further enhance and protect community health.

\section{Limitations}

The most important limitations of the analysis of the survey data relate to the sampling procedures. Although we asked all shoppers to participate, not all chose to do so. Similarly, the low number of respondents who said they used SFMNP may indicate that a slightly different population attends during and after voucher season. Participants may not constitute a representative sample of SMFM shoppers, or, more likely, the neighborhood as a whole. As mentioned previously, this strategy precludes understanding the barriers that prevent market attendance. Observations by the research team and members of the advisory committee who were helping to recruit survey participants suggest that response rates were very high. Related to this, some of the first-time shoppers may have been attracted to the market over those days specifically because of the survey. Two other limitations are the small sample size and limited statistical power, and the relatively high rate of missing responses. We did run a number of tests to determine if there are demographic differences between individuals who filled out all of their survey and those who left some of their answers blank; and although there was no indication of systematic bias, more information would be necessary to test this conclusion definitively. These limitations are balanced by our mixed-methods approach, and ability to contextualize quantitative with qualitative analysis. This exploratory analysis suggests a number of questions for future investigation.

\section{Conclusion}

A number of authors have argued convincingly that dietary decision-making is highly constrained by both household circumstances and neighborhood food environments (Drewnowski \& Darmon, 2005; Kamphuis et al., 2006; Larson et al., 2009). The prioritization of the SMFM in a participatory neighborhood revitalization plan is a strong indication that residents are knowledgeable about national dietary guidelines and place a high value on nutrition. The aim of this paper was to explore data provided by market shoppers to draw conclusions about the accessibility of the market; and, by extension, about the value of SMFM as a neighborhood response to limitations in the local food environment, as well as to identify lessons that could be useful for other primarily low-income serving farmers' markets.

This analysis supports several conclusions. First, while nutritional benefits clearly increase purchasing power, most shoppers do not rely exclusively on these programs. Both nutritional subsidies and cash purchases are likely to be important for the long-term sustainability of the market. In addition, the market draws heavily from the local neighborhood, and shoppers are generally satisfied with the operation of the market. Thus, involvement of local residents in the planning and operation of the market and advertising strategies that build on informal networks, such as yard signs and fliers, will be important to increasing neighborhood participation. Finally, there may be evidence that individuals with chronic health problems prioritize spending on fruits and vegetables, or that their shopping patterns are systematically different in some other way. Harnessing this awareness through programs geared toward increasing their access to and intake of healthy foods could expand the market impact on residents' eating habits. Taken together, this is evidence that the SMFM is achieving the objectives of SoMeRAP and the SMFM Steering Committee to address the neighborhood food environment. Consistent with the findings of other investigators, the participatory origins of this market, along with the continued participation of residents in planning and operation, appear to be an important determinant of this success.

This analysis also supports the need for further investigation of potential barriers to attendance, 
including hours of operation, lack of transportation, and limitations in household food budgets. Understanding how individuals and households confront food-related decisions on a day-to-day basis is critical to understanding the interaction of environment and household circumstances. The SMFM research team will build from these and other results to undertake (1) a systematic assessment of perceptions of the market through doorto-door surveys; (2) a longitudinal assessment of the impact of market participation on diet and body composition; and (3) an ethnographic exploration of the role of the market in individual and household choices.

\section{Acknowledgements}

We would like to thank all of the individuals who helped facilitate this research. This includes staff from The Works, Inc. and members of the SMFM Advisory Committee, especially Patricia Lacy, Karen Spencer McGee, Donna Owens, Rhonda Rucker, Curtis Thomas and Connie Binkowitz who provided invaluable feedback on research strategies and logistical support. It also includes the many students from the University of Memphis Anthropology and City and Regional Planning programs who helped substantially with data collection and the vendors and attendees who took time to answer our questions. Finally, we would like to thank two anonymous reviewers for their feedback on earlier versions of the paper.

\section{References}

Alexander, J. (2011). Making the senior farmers market voucher program work. Retrieved 11/10/ 2012 from http://www.commercialappeal.com/news/ 2011/aug/16/josephine-alexander-making-thesenior-farmers/

Alkon, A. H. (2008). From value to values: Sustainable consumption at farmers markets. Agriculture and Human V alues, 25(4), 487-498. http://dx.doi.org/10.1007/s10460-008-9136-y

Allen, P. (1999). Reweaving the food security safety net: Mediating entitlement and entrepreneurship. Agriculture and Human Values, 16(2), 117-129. http://dx.doi.org/10.1023/A:1007593210496

Andreatta, S., \& Wickliffe, W. I. (2002). Managing farmer and consumer expectations: A study of a
North Carolina farmers market. Human Organization, 61(2), 167-176.

Anliker, J. A., Winne, M., \& Drake, L. T. (1992). An evaluation of the Connecticut farmers market coupon program. Journal of Nutrition Education, 24(4), 185-191. http://dx.doi.org/10.1016/S0022$\underline{3182(12) 81152-6}$

Balsam, A., Webber, D., \& Oehlke, B. (1994). The farmers' market coupon program for low-income elders. Journal of Nutrition for the Elderly, 13(4), 35-42. http://dx.doi.org/10.1300/J052v13n04_05

Baxter, A. J., Coyne, T., \& McClintock, C. (2006). Dietary patterns and metabolic syndrome - A review of epidemiologic evidence. Asia Pacific Journal of Clinical Nutrition, 15(2), 134-142. PMid:16672196

Beaulac, J., Kristjansson, E., \& Cummins, S. (2009). A systematic review of food deserts, 1966-2007. Prevention of Chronic Disease, 6(3), 1-10.

Becker, G. S. (2006). Farmers' markets: The USD A role. Congressional Research Service Report for Congress. http://congressionalresearch.com/ RS21652/document.php?study $=$ Farmers + Markets + The+USDA+Role

Boyle, M., Stone-Franciso, S., \& Samuels, S. E. (2006). Environmental strategies and policies to support healthy eating and physical activity in low-income communities. Journal of Hunger and Environmental Nutrition, 1(2), 3-25. http://dx.doi.org/10.1300/J477v01n02_02

Brown, A. (2001). Counting farmers markets. Geographical Review, 91(4), 655-674. http://dx.doi.org/10.2307/3594724

Bubinas, K. (2011). Farmers markets in the postindustrial city. City \& Society, 23(2), 154-172. http://dx.doi.org/10.1111/j.1548744X.2011.01060.x

Dinour, L. M., Bergen, D., \& Yeh, M. (2007). The food insecurity-obesity paradox: A review of the literature and the role food stamps may play. Journal of the American Dietetic Association, 107(11), 19521961. http://dx.doi.org/10.1016/j.jada.2007.08.006

Drewnowski, A., \& Darmon, N. (2005). The economics of obesity: Dietary energy density and energy cost. The American Journal of Clinical Nutrition, 82(1), 265S273S. PMid:16002835

Eisenhauer, E. (2001). In poor health: Supermarket redlining and urban nutrition. Geojournal, 53(2), 125-133. http://dx.doi.org/10.1023/A:1015772503007 
Faulk, D. (2006). The process and practice of downtown revitalization. Review of Policy Research, 23(2), 625645. http://dx.doi.org/10.1111/j.15411338.2006.00219.x

Freire, P. (2000). Pedagogy of the oppressed. New York, NY: Continuum International Publishing Group.

George, D. R., Kraschnewski, J. L., \& Rovniak, L. S. (2011). Public health potential of farmers' markets on medical center campuses: A case study from Penn state Milton S. Hershey medical center. American Journal of Public Health, 101(12), 2226-2232. http://dx.doi.org/10.2105/AJPH.2011.300197

Gibson, D. M. (2011). The neighborhood food environment and adult weight status: Estimates from longitudinal data. American Journal of Public Health, 101(1), 71-78. http://dx.doi.org/10.2105/AJPH.2009.187567

Gillespie, G., Hilchey, D. L., Hinrichs, C. C., \& Feenstra, G. (2007). Farmers' markets as keystones in rebuilding local and regional food systems. In C. C. Hinrichs, \& T. A. Lyson (Eds.), Remaking the North American food system: Strategies for sustainability (pp. 65-83). Lincoln, Nebraska: University of Nebraska Press.

Guthman, J., Morris, A. W., \& Allen, P. (2006). Squaring farm security and food security in two types of alternative food institutions. Rural Sociology, 71(4), 662-684. Retrieved from http://onlinelibrary.wiley. com/journal/10.1111/\%28ISSN\%291549-0831

Hendrickson, D., Smith, C., \& Eikenberry, N. (2006). Fruit and vegetable access in four low-income food deserts communities in Minnesota. Agriculture and Human Values, 23(3), 371-383. http://dx.doi.org/10.1007/s10460-006-9002-8

Herman, D. R., Harrison, G. G., Afifi, A. A., \& Jenks, E. (2008). Effect of a targeted subsidy on intake of fruits and vegetables among low-income women in the Special Supplemental Nutrition Program for Women, Infants, and Children. American Journal of Public Health, 98(1), 98-105. http://dx.doi.org/10.2105/AJPH.2005.079418

Hu, F. B. (2003). Plant-based foods and prevention of cardiovascular disease: An overview. The American Journal of Clinical Nutrition, 78 (3 Suppl), 544S-551S. PMid:12936948

Izumi, B. T., Zenk, S. N., Schulz, A. J., Mentz, G. B., \& Wilson, C. (2011). Associations between neighborhood availability and individual consumption of dark-green and orange vegetables among ethnically diverse adults in Detroit. Journal of the American Dietetic Association, 111(2), 274-279. http://dx.doi.org/10.1016/j.jada.2010.10.044

Johnson, D. B., Beaudoin, S., Smith, L. T., Beresford, S. A., \& LoGerfo, J. P. (2004). Increasing fruit and vegetable intake in homebound elders: The Seattle senior farmers' market nutrition pilot program. Preventing Chronic Disease, 1(1), A03. PMid:15634365 PMCid:PMC544526

Kamphuis, C. B., Giskes, K., de Bruijn, G. J., WendelVos, W., Brug, J., \& van Lenthe, F. J. (2006). Environmental determinants of fruit and vegetable consumption among adults: A systematic review. The British Journal of Nutrition, 96(4), 620-635. PMid:17010219

Lambert-Pennington, K., \& Reardon, K. (2009). South Memphis revitalization action plan: A people's blueprint for building a more vibrant, sustainable and just community. Memphis, TN: St. Andrew AME Church. Approved by the City of Memphis March 9, 2010. http://www.memphis.edu/planning/SoMe_RAP/ SoMeRAP Draft 11.10.09.pdf

Lambert-Pennington, K., Reardon, K. M., \& Robinson, K. S. (2011). Revitalizing south Memphis through an interdisciplinary community-university development partnership. Michigan Journal of Community Service Learning, 17(2), 59-70.

Larsen, K., \& Gilliland, J. (2008). Mapping the evolution of 'food deserts' in a Canadian city: Supermarket accessibility in London, Ontario, 1961-2005. International Journal of Health Geographics, 7(1), 16. http://dx.doi.org/10.1186/1476-072X-7-16

Larsen, K., \& Gilliland, J. (2009). A farmers' market in a food desert: Evaluating impacts on the price and availability of healthy food. Health \& Place, 15(4), 1158-1162. http://dx.doi.org/10.1016/ j.healthplace.2009.06.007

Larson, N. I., Story, M. T., \& Nelson, M. C. (2009). Neighborhood environments: Disparities in access to healthy foods in the U.S. American Journal of Preventive Medicine, 36(1), 74-81. http://dx.doi.org/10.1016/j.amepre.2008.09.025

Lee, J. S., Gundersen, C., Cook, J., Laraia, B., \& Johnson, M. A. (2012). Food insecurity and health across the lifespan. Advances in Nutrition (Bethesda, Md.), 3(5), 744-745. http://dx.doi.org/10.3945/an.112.002543 
Lyson, T. A., Gillespie Jr, G. W., \& Hilchey, D. (1995). Farmers' markets and the local community: Bridging the formal and informal economy. American Journal of Alternative Agriculture, 10(3), 108-112. http://dx.doi.org/10.1017/S0889189300006251

Markowitz, L. (2010). Expanding access and alternatives: Building farmers' markets in lowincome communities. Food and Foodways, 18, 66-80. http://dx.doi.org/10.1080/07409711003708512

McCormack, L. A., Laska, M. N., Larson, N. I., \& Story, M. (2010). Review of the nutritional implications of farmers' markets and community gardens: A call for evaluation and research efforts. Journal of the American Dietetic Association, 110(3), 399-408. http://dx.doi.org/10.1016/j.jada.2009.11.023

Michimi, A., \& Wimberly, M. C. (2010). Associations of supermarket accessibility with obesity and fruit and vegetable consumption in the conterminous United States. International Journal of Health Geographics, 9, 49. http://dx.doi.org/10.1186/1476-072X-9-49

Payet, J., Gilles, M., \& Howat, P. (2005). Gascoyne growers market: A sustainable health promotion activity developed in partnership with the community. Australian Journal of Rural Health, 13(5), 309-314. http://dx.doi.org/10.1111/j.14401584.2005.00722.x

Racine, E. F., Smith Vaughn, A., \& Laditka, S. B. (2010). Farmers' market use among African-American women participating in the Special Supplemental Nutrition Program for Women, Infants, and Children. Journal of the American Dietetic Association, 110(3), 441-446. http://dx.doi.org/10.1016/j.jada.2009.11.019

Reardon, K. M. (1998). Participatory action research as service learning. New Directions for Teaching and Learning, 1998(73), 57-64. http://dx.doi.org/10.1002/tl.7307

Reardon, K. M. (2005). Empowerment planning in East St. Louis, Illinois: A peoples' response to the deindustrialization blues. City, 9(1), 85-100. http://dx.doi.org/10.1080/13604810500128629

Reardon, K. M., Ionescu-Heroiu, M., \& Rumbach, A. J. (2008). Equity planning in post-Hurricane Katrina New Orleans: Lessons from the Ninth Ward. Cityscape, 57-76.

Roblin, L. (2007). Childhood obesity: Food, nutrient, and eating-habit trends and influences. Applied Physiology, Nutrition, and Metabolism = Physiologie
Appliquee, Nutrition Et Metabolisme, 32(4), 635-645. http://dx.doi.org/10.1139/H07-046

Ruelas, V., Iverson, E., Kiekel, P., \& Peters, A. (2012). The role of farmers' markets in two low income, urban communities. Journal of Community Health, 37(3), 554-562. http://dx.doi.org/10.1007/s10900011-9479-y

Rundle, A., Neckerman, K. M., Freeman, L., Lovasi, G. S., Purciel, M., Quinn, J., . . . Weiss, C. (2009). Neighborhood food environment and walkability predict obesity in New York City. Environmental Health Perspectives, 117(3), 442-447. Retrieved from http://ehp.niehs.nih.gov/

Schroder, H., Marrugat, J., \& Covas, M. I. (2006). High monetary costs of dietary patterns associated with lower body mass index: A population-based study. International Journal of Obesity (2005), 30(10), 1574 1579. http://dx.doi.org/10.1038/sj.ijo.0803308

South Memphis Farmers Market. (2013). South Memphis farmers market: Our mission. Retrieved 6/11/2013 from http://somefm.org/mission/

Szmigin, I., Maddock, S., \& Carrigan, M. (2003). Conceptualising community consumption: Farmers' markets and the older consumer. British Food Journal, 105(8), 542-550. http://dx.doi.org/10.1108/00070700310497291

United States Department of Agriculture. (2013). Food deserts. Retrieved 10/27/2013, from http://apps. ams.usda.gov/fooddeserts/foodDeserts.aspx

Walker, R. E., Keane, C. R., \& Burke, J. G. (2010). Disparities and access to healthy foods in the United States: A review of the food deserts literature. Health and Place, 16(5), 876-884. http://dx.doi.org/10.1016/j.healthplace.2010. $\underline{04.013}$

Winne, M. (2008). Closing the food gap: Resetting the table in the land of plenty. Boston: Beacon Press.

Young, C., Karpyn, A., Uy, N., Wich, K., \& Glyn, J. (2011). Farmers' markets in low income communities: Impact of community environment, food programs and public policy. Community Development: Journal of the Community Development Society, 42(2), 208(13).

Zick, C., Smith, K. R., Fan, J. X., Brown, B. B., Yamada, I., \& Kowaleski-Jones, L. (2009). Running to the store? The relationship between neighborhood environments and risk of obesity. Social Science \& Medicine, 69(10), 1493-1500. PMid:19766372 